\title{
Uzaktan Algılanmış Görüntülerin SURF Özellik Verileri ve RANSAC Algoritması ile Otomatik Çakıştırılması
}

\author{
Automatic Registration of Remotely Sensed Images by Using SURF Features and RANSAC \\ Algorithm
}

Mustafa DïHKAN*

Karadeniz Teknik Üniversitesi, Mühendislik Fakültesi, Harita Mühendisliği Bölümü, 61080, Trabzon

• Geliş tarihi / Received: 22.11.2018 • Düzeltilerek geliş tarihi / Received in revised form: 31.01 .2019 • Kabul tarihi / Accepted: 11.02 .2019

\begin{abstract}
$\ddot{O} z$
Günümüzde algılayıcı çeşitliliği ile birlikte artan veri yoğunluğu sebebiyle, uzaktan algılama ve fotogrametrik değerlendirme süreçlerinde çakıştırma aşamasının otomatizasyonuna yönelik araştırmalar yoğunlaşmışıı. Otomatik çakıştırma algoritmalarından; çevresel izleme, değişim analizi, sınıflandırma, görüntü kaynaştırma gibi birçok çalışmada faydalanılmaktadır. Bu çalışmada farklı zamanlarda değişik sensörlerce (alıcılarla) kaydedilen uzaktan algılanmış çok bantlı görüntülerin otomatik çakıştırılmasına yönelik özellik tabanlı bir yaklaşım önerilmiştir. $\mathrm{Bu}$ yaklaşımın özellik çıkarma aşamasında SURF (Speeded-up Robust Feature) algoritmasının TBA (Temel Bileşen Analizi) yardımıyla iyileştirilmiş çok bantlı veri setlerinin ilk bandına uygulanması yoluyla verinin tüm bantlarındaki spektral bilgiden optimum düzeyde faydalanılmıştır. Bu aşamada belirlenen ilgi noktalarına ilişkin 64 boyutlu özellik vektörleri yardımıyla hesaplanan KFT(Karesel Farklar Toplamı) değerleri kritize edilerek eşlenik noktalar tespit edilmiştir. Ardından eşlenik noktalar arasında zayıf olanlar RANSAC (Random Sample Consensus) yardımıyla elemine edilerek kalan noktalar ile projektif dönüşüm modeli için homografi tanımlanmıştır. Son aşamada hesaplanan homografi matrisi kullanılarak geometrik dönüşüm uygulanan görüntüler yeniden örnekleme sonrasında jeoreferanslı olarak kaydedilmiştir. Önerilen yaklaşımın testi için 2003, 2008 ve 2015 tarihlerinde farklı sensörlerce algılanmış çok bantlı dijital hava görüntülerinden faydalanılmıştır. Bunlardan 2015 tarihli görüntü ortofoto olup referans görüntüsü olarak kullanılmıştır. Çalışmada önerilen yaklaşımın uygulanması sonucunda; 2003 görüntüsü için $\pm 0.61 \mathrm{~m}, 2008$ görüntüsü için ise $\pm 0.53 \mathrm{~m} \mathrm{KOH}$ (Karesel Ortalama Hata) düzeyinde konumsal doğruluk elde edilmiştir.
\end{abstract}

Anahtar kelimeler: Otomatik görüntü çakıştırılması, RANSAC, SURF, TBA

\begin{abstract}
Intensive work has been carried out for optimization of automatic registration using remotely sensed data and photogrammetric techniques because of very large and various datasets availability. Automatic registration is used in many remote sensing mapping applications such as environmental monitoring, change detection, classification, image fusion, etc. In this study, a feature based approach was proposed for automatic registration which can be used for automatic registration of multispectral images acquired in different periods. This technique suggests an optimization of multiband spectral data generated by PCA (Principal Component Analysis) transformation. The multispectral image data was first evaluated using PCA then the SURF (Speeded up Robust Feature) algorithm was applied on the optimized first band of the processed image to detect interest points. In order to decide on matching points used SSD (Sum of Square Distances) values are calculated using interest points data with 64 dimensional feature vectors. As a step forward weak points were eliminated by applying RANSAC (Random Sample Consensus) method and the remaining point data were used for determining homography which is necessary for projective transformation. In the last step, georeferenced images that were geometrically transformed using homography matrix were saved after resampling process. In order to test the proposed approach multispectral aerial images from 2003, 2008 and 2015 were used. The orthophoto image of 2015 was used as reference data. As a result spatial accuracies were found with RMSE values as $\pm 0.61 \mathrm{~m}$ and $\pm 0.53 \mathrm{~m}$ for the years 2003 and 2008 respectively.
\end{abstract}

Keywords: Automatic image registration, RANSAC, SURF, PCA

\footnotetext{
* Mustafa DïHKAN; mdihkan@ktu.edu.tr; Tel: (0462) 377 27 68; orcid.org/0000-0002-0027-236X
} 


\section{Giriş}

Son y1llarda Uzaktan Algilama ve Fotogrametri alanlarında meydana gelen gelişim süreçleri; yüksek konumsal, spektral, radyometrik ve zamansal çözünürlüklü çok boyutlu dijital görüntü verilerinin yoğun olarak elde edilebilmesine olanak tanımaktadır. Veri yoğunluğunda meydana gelen bu artış söz konusu alanlardaki çeşitli temel operasyonların otomatizasyon düzeyinin önemli oranda arttırılması gerekliliğini beraberinde getirmiştir. $\mathrm{Bu}$ uygulamaların en önemlilerinden birisi hiç şüphesiz görüntü çakıştırılması olup çevresel izleme, değişim analizi, görüntü kaynaştırma gibi askeri veya sivil amaçlı faaliyetlerin önemli çoğunluğunda gerçekleştirilmesi gereklidir. Uzaktan algılanmış görüntülerde çakıştırma kavramı aynı alana ait iki veya daha fazla sayıda; farklı görüş noktalarından, aynı/farklı sensörlerle, aynı/farklı zamanlarda kaydedilmiş görüntü verilerinin eşleştirilmesi olarak ifade edilebilir (Fonseca ve Manjunath, 1996). Literatürde dijital görüntülerin otomatik çakıştırılması probleminin çözümüne yönelik olarak yapılmış çalışmalarda çeşitli yaklaşımlar geliştirilmiş olmasına karşın, uydu/hava görüntüleri söz konusu olduğunda bu işlem önerilen metotlar ile yeterli doğruluk düzeyine ulaşılamamasından ötürü çoğu zaman manuel olarak gerçekleştirilmektedir (Zitova ve Flusser, 2003; Gonçalves vd., 2011a). Uzaktan algılanmış görüntüler çoğu zaman oldukça geniş alanlarda, çok çeşitli geometrik ve spektral karakteristiğe sahip yüzeylere ilişkin bilgi içeren veri setleridir. Özellikle yüzey geometrisinden kaynaklanan değişken rölyef etkileri, farklı alım noktası konumlarından ötürü meydana gelen geometrik deformasyonlar, alım zamanındaki farklardan dolayı yüzey aydınlanmasında meydana gelen değişimler, görüntü radyometrisinde meydana gelen farklılıklar, farklı sensör kullanımından ötürü oluşan değişken distorsiyon etkileri gibi nedenlerle uzaktan algılanmış görüntülerin otomatik çakıştırılması işlemini oldukça güçleştirmektedir (Yang vd., 2017).

Uzaktan algılanmış görüntülerin otomatik çakıştırma süreci genel olarak; özellik çıkarma, özellik eşleştirme, geometrik dönüşüm ve yeniden örnekleme gibi aşamalardan oluşmaktadır. Literatürde otomatik çakıştırma teknikleri faydalanılan özellik çıkarma algoritmasına bağlı olarak alan tabanlı ve özellik tabanlı olmak üzere iki ana kategoride değerlendirilmektedir (Brown, 1992). Alan tabanlı yaklaşımlarda referans ve rektifiye edilecek görüntüler üzerinde seçilen görüntü pencerelerindeki piksel gri değerlerinden faydalanılarak alansal benzerlik düzeyi belirlenebilmekte ve görüntü yöneltmesi için gerekli parametreler elde edilebilmektedir. Bu tür yaklaşımlar basit görüntüler için kullanılabilir olmalarına karşın; yeterli ayırt edici detay barındırmayan, monoton örüntüler içeren, gürültü oranı yüksek, karmaşık distorsiyon etkileri altında olan ve aralarında ciddi radyometrik farklılıklar bulunan görüntü çiftlerinin çakıştırılmasında arama uzayı genişleyerek dönüşüm hesaplamalarını oldukça kompleks ve zaman alıcı bir hale getirmektedir ( $\mathrm{Li}$ vd., 2009). Özellik tabanlı yaklaşımlarda ilk aşamada kenar, köşe, eğri, spesifik bölge merkezleri gibi özelliklerin görüntülerden çıkarılmasının ardından bunlar arasındaki korelasyon düzeyi irdelenerek görüntüler arasındaki dönüşüm doğruluğu optimum seviyeye çıkarılmaya çalışılmaktadır ( $\mathrm{Li}$ vd., 2009, Acar vd., 2017). Hiç şüphesiz bu tür yaklaşımların özellik çıkarma aşamasında kullanılan; Harris (Harris ve Stephens, 1988), SUSAN (Smallest Univalue Segment Assimilating Nucleus) (Smith ve Brady, 1997), FAST (Features from Accelerated Segment Test) (Rosten ve Drummond, 2006), SIFT (Scale Invariant Feature Transform) (Lowe, 2004), SURF (Bay vd., 2008), vb. algoritmalar dönüşüm doğruluğu üzerinde önemli oranda etkili olabilmektedir. SIFT algoritması özellikle aynı bölgeyi kapsayan uzaktan algılanmış görüntüler arasında büyük oranlarda değişken olabilen; dönüklük, öteleme ve ölçek gibi konumsal dönüşüm parametrelerinden tamamen bağımsız, görüntü alım noktası konum değişimi ve yüzey aydınlanma farklılıklarından kısmen bağımsız olarak çalışabilmesi sebebiyle yaygın olarak kullanılmaktadır (Ma vd., 2017). Bununla birlikte SIFT algoritmasının en önemli dezavantajı tespit ettiği her bir nokta için oluşturduğu 128 boyutlu özellik vektörü kullanılarak yapılan eşleştirme işleminin oldukça zaman alıcı olmasıdır. Aynı koşullar altında eşlenik görüntüler üzerinde en az SIFT algoritmasi kadar iyi performans elde edebilmek ve işlem süresini önemli oranda azaltabilmek amaciyla Bay vd. (2008) tarafindan SURF algoritması geliştirilmiştir.

$\mathrm{Bu}$ çalışmada uzaktan algılanmış çok bantlı görüntülerin otomatik olarak çakıştırılmasına yönelik bir yaklaşım önerilmiştir. Bu amaçla ilk aşamada çok bantlı veri setlerinin tüm bantlarındaki spektral bilgiden optimum oranda faydalanabilmek adına TBA uygulanmıştır. Ardından özellik çıkarma aşamasında SURF algoritması birinci ana bileşen bandına uygulanarak ilgi noktaları tespit edilmiştir. Sonrasında özellik eşleştirme adımında farklı 
görüntüler üzerindeki ilgi noktaları arasından eşlenik çiftler belirlenmiştir. Bu işlemin ardından RANSAC yardımıyla zayıf eşleşmeler elimine edilmiştir. Son aşamada ise kalan güçlü noktalar ile projektif dönüşüm modeli için homografi tanımlanarak görüntülere geometrik dönüşüm uygulanmış ve çakıştırma işlemi tamamlanmıştır. Önerilen yaklaşıma ilişkin akış diyagramı Şekil 1 de verilmiştir.

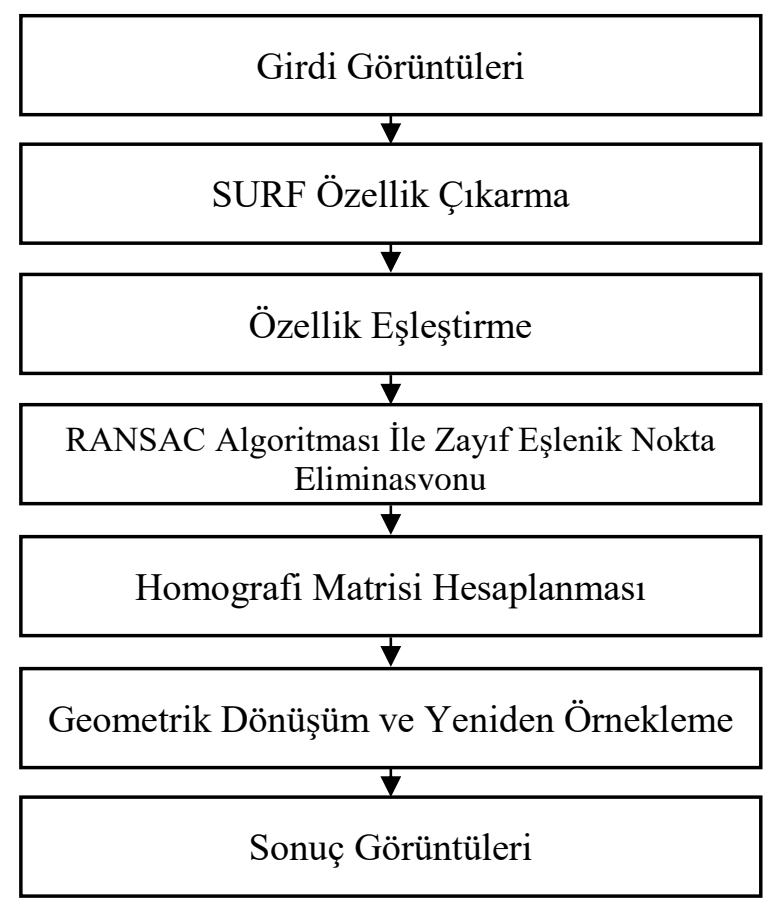

Şekil 1. Önerilen yaklaşıma ilişkin akış diyagramı

\subsection{SURF Algoritması ve Özellik Çıkarma}

SURF özellik yakalama algoritması ikinci derece Hessian matris determinantına dayalı olarak çalışmaktadır. Algoritmada hesaplama hızını arttırabilmek için kutu filtre ve integral görüntülerinden faydalanılmaktadır. İntegral görüntüsü her bir $p(x, y)$ noktasına karşılık gelen, bu nokta merkezde kalmak üzere soldan-sağa ve yukarıdan-aşağıya oluşan dörtgensel bölgedeki tüm piksellerin değerleri toplamının meydana getirdiği kümülatif bir görüntüdür. Her bir $X$ noktası için $\sigma$ ölçeğinde tanımlanan $H_{(x, \sigma)}$ Hessian matrisi eşitlik (1)'de ifade edilmiştir.

$$
H(x, \sigma)=\left[\begin{array}{ll}
\operatorname{Lxx}(x, \sigma) & \operatorname{Lxy}(x, \sigma) \\
\operatorname{Lxy}(x, \sigma) & \operatorname{Lyy}(x, \sigma)
\end{array}\right]
$$

Eşitlikte $L x x(x, \sigma), X$ noktasındaki görüntü ile Gaussian ikinci dereceden türevinin (LoG) konvolüsyonunu ifade etmektedir. SURF algoritmasında hesaplama hızını arttırmak için kullanılan kutu filtre sayesinde Gaussian ikinci dereceden yaklaşık kısmi türev değerleri elde edilmektedir. Bu aşamada (2) eşitliği yardımıyla elde edilen yeni Hessian matris için determinant değeri hesaplanmaktadır (Bay vd. 2008).

$$
\operatorname{det}\left(H_{\text {yaklassk }}\right)=D_{x x} D_{y y}-\left(0.9 D_{x y}\right)^{2}
$$

Eşitlikte $D_{x x}, D_{y y}$ ve $D_{x y}$ kutu filtre yardımıyla yaklaşık değerleri hesaplanan $L_{x x}, L_{y y}$ ve $L_{x y}$ Hessian matris elemanların ifade etmektedir.

Farklı görüntü ölçeklerinde ilgi noktaların belirlenebilmesi için ölçek uzaylarından faydalanılmaktadır. Ölçek uzayları genellikle görüntü piramitleri olarak tanımlanmaktadır. Bir üst piramit seviyesine ulaşabilmek için görüntüler; Gauss filtresi yardımıla tekrarlı olarak yumuşatılmakta ve ard1 sıra alt-örnekleme operasyonu uygulanmaktadır. SURF algoritmasinda yoğun hesaplama gerektiren ve oldukça zaman alıcı bu işlemleri hızlandırabilmek amaciyla kutu filtresi ve integral görüntülerinden faydalanılmaktadır. Bu sayede çeşitli boyutlarda filtreler doğrudan orjinal görüntüye uygulanabilmektedir. $\mathrm{Bu}$ aşamada filtre boyutunun üstölçeklemesi yoluyla ölçek uzayı analiz edilebilmektedir.

Algoritmada ölçek uzayında tespit edilen ilgi noktaları arasından zayıf olanların ayıklanabilmesi amaciyla $3 \times 3 \times 3$ komşuluğunda maksimum olmayanların eliminasyonu tekniğinden faydalanılmaktadır. Bu aşamada her bir piksel; ölçek uzayında bir üst ve bir alt boyutta 9, mevcut bulunduğu boyutta ise 8 komşusu olmak üzere toplam 26 komşusu ile karşılaştırmalı olarak analiz edilmektedir. Bu amaçla Brown vd. (2002) tarafindan önerilen yaklaşım ile Hessian matrisinin determinantının maksimumları ölçek ve görüntü uzayında nokta konumlarının tespiti için enterpole edilmektedir. Güçlü ilgi noktalarının konumları Hessian matrisinin türevi kullanılarak belirlenebilmektedir. $\mathrm{Bu}$ aşamada tüm komşu pikseller ile mutlak fark değerlerinin hesaplanması yoluyla türev alma işlemi gerçekleştirilmekte ve belirlenen eşik değere göre iteratif olarak kritize edilerek güçlü ilgi noktası konumları tespit edilmektedir.

Güçlü ilgi noktalarının belirlenmesinin ardından bu noktaların komşu pikselleri yardımıyla özellik vektörleri oluşturulmaktadır. Özellik vektörlerinden farklı görüntüler üzerindeki eşlenik noktaların eşleştirilmesi sürecinde faydalanımaktadır. SURF özellik tanımlayıcısı benzerlik 
tabanlı olarak çalışmaktadır. Görüntü dönüklüğüne karşı değişmezliğin sağlanabilmesi amacıyla her bir ilgi noktası için 6s (ilgi noktasına ilişkin ölçek düzeyini $\mathrm{s}$ parametresi ile ifade edilmektedir) yarıçapında dairesel komşulukta Haar dalgacık tepkisine dayalı olarak tanımlanan tekrarlanabilir baskın yön bilgisi belirlenmektedir. Dalgacık cevapları ilgi noktasında merkezlenmiş bir Gaussian $(\sigma=2 \mathrm{~s})$ kernel fonksiyonu ile ağırlıklandırılmaktadır. Bu aşamada her bir ilgi noktası merkezinde konumlanacak şekilde 20s boyutunda dörtgensel bir tanımlayıcı pencere oluşturulmasının ardından bu pencere $4 \times 4$ dörtgensel alt-bölgeye ayrılmaktadır. Bu 16 altbölgenin her biri için $x$ ve $y$ yönlerinde $d_{x}$ ve $d_{y}$ Haar dalgacık tepki değerleri hesaplanmakta ve bu değerler Gauss kerneli ile ağırlıklandırılmaktadır. Ayrıca Haar dalgacık tepki değerlerinin mutlak değerleri $\left|d_{x}\right|$ ve $\left|d_{y}\right|$ 'de hesaplanmaktadır. Her bir alt bölge için toplam 4 değer elde edilmektedir. Bu sayede 64 boyutlu özellik vektörleri her bir ilgi noktası için belirlenmektedir.

\section{2. Özellik Eşleştirme}

Farklı görüntü alım noktalarından algılanmış görüntüler üzerinde tespit edilen ilgi noktalarına ilişkin oluşturulan 64 boyutlu SURF özellik vektörleri sayesinde bu noktalardan eşlenik olanlar tespit edilebilmektedir. $\mathrm{Bu}$ amaçla öncelikle tüm görüntü çiftleri için KFT mesafe matrisleri oluşturulmaktadır. Sonrasında ikinci en yakın mesafe değeri ilk en yakın mesafe değerinden öncül olarak belirlenen bir orandan fazla olduğunda bu ilgi noktaları eşlenik olarak atanmaktadır.

\subsection{RANSAC İle Güçlü Eşlenik Nokta Tespiti ve Homografi Hesaplanmast}

Son yıllarda çeşitli alanlarda üretilen veri kümelerinin seçilen matematik modele uyumluluk düzeyinin iteratif olarak irdelenmesi ve veri içinden çözümde istenilen düzeyde başarım sağlayanların otomatik olarak ayıklanmasına yönelik olarak RANSAC metodundan yaygın olarak faydalanılmaktadır (Fishcler ve Boller, 1987). Uzaktan algılanmış görüntülerin otomatik çakıştırılması sürecinde özellik çıkarma ve eşleştirme aşamaları sonucunda üretilen eşlenik noktalar arasında zayıf olanların elemine edilmesi gerekmektedir. Bu aşamada RANSAC yardımı ile yapılan iteratif analizler sonucunda zayıf eşlenik noktalar elenerek homografi en yüksek doğruluk düzeyinde hesaplanabilmektedir (Hartley ve Zisserman, 2003). Çok-bakışlı eşlenik görüntüler arasında geometrik ilişki homografi yardımıyla kurulabilmektedir (3). Homografi matrisi benzerlik, afin, projektif, vb. çeşitli geometrik dönüşüm modelleri için tanımlanabilmektedir. 8 serbestlik derecesine sahip projektif dönüşüm modeli için homografi matrisi (4) elemanları en az 4 veya daha fazla sayıda eşlenik nokta çifti yardımıyla hesaplanabilmektedir.

$$
x^{\prime}=H x
$$

Eşitlikte $x$ referans görüntü üzerindeki noktaları, $x^{\prime}$ ikinci görüntü üzerindeki noktaları, $H$ homografi matrisini ifade etmektedir.

$$
H=\left[\begin{array}{lll}
h_{1} & h_{2} & h_{3} \\
h_{4} & h_{5} & h_{6} \\
h_{7} & h_{8} & h_{9}
\end{array}\right]
$$

RANSAC yardımı ile yapılan optimizasyon sonucunda veri kümesi içindeki noktalar arasında eşleşme düzeyi yüksek olan güçlü noktalar kullanılarak $H$ matrisi elemanları dengelemeli olarak hesaplanmakta ve iki görüntü arasında projektif dönüşüm için gerekli tüm parametreler elde edilebilmektedir.

\section{Yöntem}

Çalışmada farklı tarihlerde farklı sensörlerce kaydedilmiş uzaktan algılanmış görüntülerin otomatik çakıştırılmasına yönelik özellik tabanlı bir yaklaşım geliştirilmesi ve elde edilen sonuçların test edilmesi hedeflenmiştir. Bu amaçla USGS portalı üzerinden Amerika Birleşik Devletleri San Francisco Eyaletinde bulunan; yarı-kentsel arazi örtüsü/kullanım karakterine sahip, spektal çeşitliliğin yoğun olduğu, yüzölçümü 288 hektar olan bir bölge test alanı olarak seçilmiştir. Çalışma bölgesine ait sırasıyla; ADS40, ADS60 ve ADS100 sensörleri tarafindan 2003,2008 ve 2015 y1llarında algılanmış, $30 \mathrm{~cm}$ YÖA (Yer Örnekleme Aralığı) boyutuna sahip, 3 çok-bantlı (Kırmızı/Yeşil/Mavi) dijital hava görüntüsü temin edilmiştir (Şekil 2a, b ve c). Bunlar arasinda 2015 tarihine ait olan görüntü ortorektifiye edilmiş olup; UTM projeksiyonu, NAD83 datumunda referanslandırılmıştır. Söz konusu ortofoto görüntüden çalışma kapsamında referans görüntü olarak faydalanılmıştır.

Şekil 2 de verilen akış diyagramında önerilen yaklaşım kapsamında uygulanan özellik tabanlı otomatik çakıştırma prosedürü görülebilmektedir. Çok yüksek konumsal çözünürlüklü çok bantlı uzaktan algılanmış görüntü verileri söz konusu olduğunda bu tür verilerin sahip olduğu detay 
yoğunluğu beraberinde spektral ve radyometrik bilginin önemli oranda çeşitlilik kazanmasına ve farklı bantlarda temsil edilebilmesine olanak sağlamaktadır. Önerilen yaklaşımın ilk aşamasında bu spektral ve radyometrik bilgi çeșitliliğinden optimum düzeyde faydalanabilme amacıyla ana bileşenler dönüşümü yardımıyla görüntü iyileştirme uygulanmıştır. $\mathrm{Bu}$ dönüşüm çok bantlı görüntülerde farklı bantlarda bulunan diğer bantlar ile korelasyonu düşük değerli spektral bilgilerin önemli bir kısmını dönüşüm sonrasında oluşan ilk bantta toplayan bir algoritmadır (Gonçalves vd., 2011b).

Çalışmada kullanılan 3 bantlı görüntülere ana bileşenler dönüşümü uygulanması sayesinde ayırt edici spektral bilginin önemli bir kısmı dönüşüm sonrası oluşturulan 1. bantta temsil edilebilmiştir.
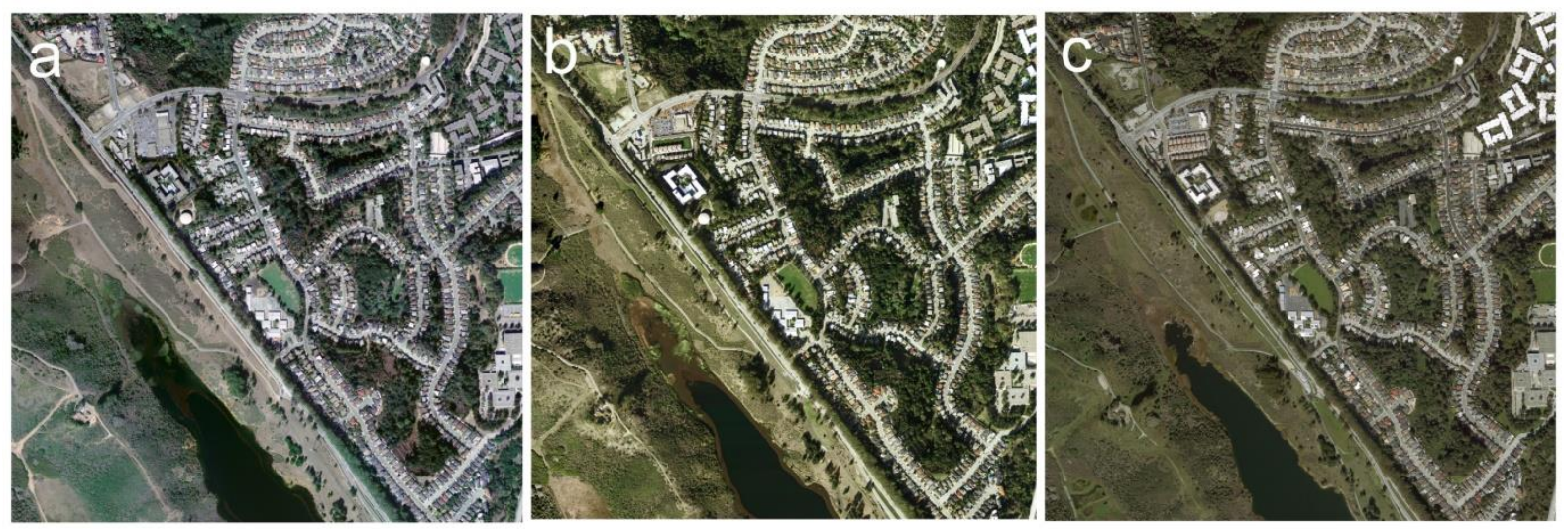

Şekil 2. (a) 2003 (b) 2008 (c) 2015 tarihli dijital hava görüntüleri
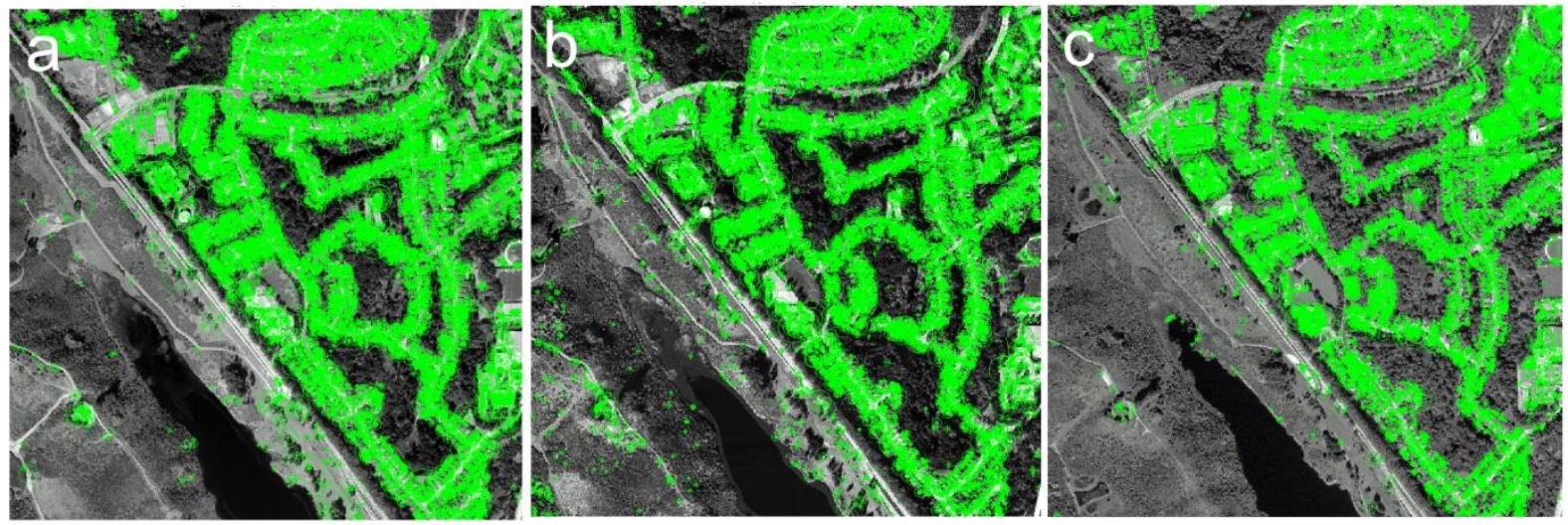

Şekil 3. (a) 2003 (b) 2008 (c) 2015 tarihli dijital hava görüntüleri üzerinde SURF ile tespit edilen ilgi noktalar1

Önerilen yaklaşımda özellik çıkarma aşamasında SURF algoritmasının 1 . ana bileşen band 1 üzerinde uygulanması sayesinde tespit edilen ilgi noktası sayısının ve eşleştirme doğruluğunun olumlu yönde etkilediği gözlemlenmiştir. $\mathrm{Bu}$ aşamada tespit edilen ilgi noktaları Şekil $3 a$, b ve c de görülebilmektedir.

Özellik eşleştirme aşamasında tespit edilen ilgi noktaları için hesaplanan 64 boyutlu özellik vektörleri yardımıyla 2003 - 2015 ve 2008 - 2015 görüntü çiftleri için KFT mesafe matrisleri oluşturulmuştur. Sonrasında KFT mesafeleri analiz edilerek eşlenik noktalar tespit edilmiştir. $\mathrm{Bu}$ aşamada yakın özellik değerlerine sahip ilgi noktaları arasında hatalı eşlemeler meydana gelebilmektedir. $\mathrm{Bu}$ tür zayıf eşlenik noktaların veri seti içinden ayıklanması amacıyla RANSAC yardımı ile eleminasyon yapılmıştır. RANSAC yaklaşımı ile yapılan iterasyonlar sayesinde projektif dönüşüm modeline ilişkin homografi matrisleri arasından en yüksek dönüşüm doğruluğu ile çözüm sağlayan matris, ayıklanan güçlü eşlenik noktalar yardımıyla hesaplanmıştır (Şekil 4a ve b). 
Çalışmada kullanılan orto-rektifiye edilmiş referans görüntüsüne ilişkin geo-referans bilgisi yardımıyla referans görüntüsü piksel koordinat sisteminde bulunan eşlenik noktaların piksel koordinatlarına karşılık gelen UTM koordinatları belirlenmiştir. Ardından, güçlü eşlenik noktalar ile projektif dönüşüm modeli için tanımlanan homografi matrisi yardımıyla geometrik dönüşüm işlemi gerçekleştirilmiştir. Son aşamada uygulanan en yakın komşu gri değer örneklemesi ile 2003 ve 2008 girdi görüntülerin otomatik çakıştırılması gerçekleştirilmiştir (Şekil 5a, b ve c).

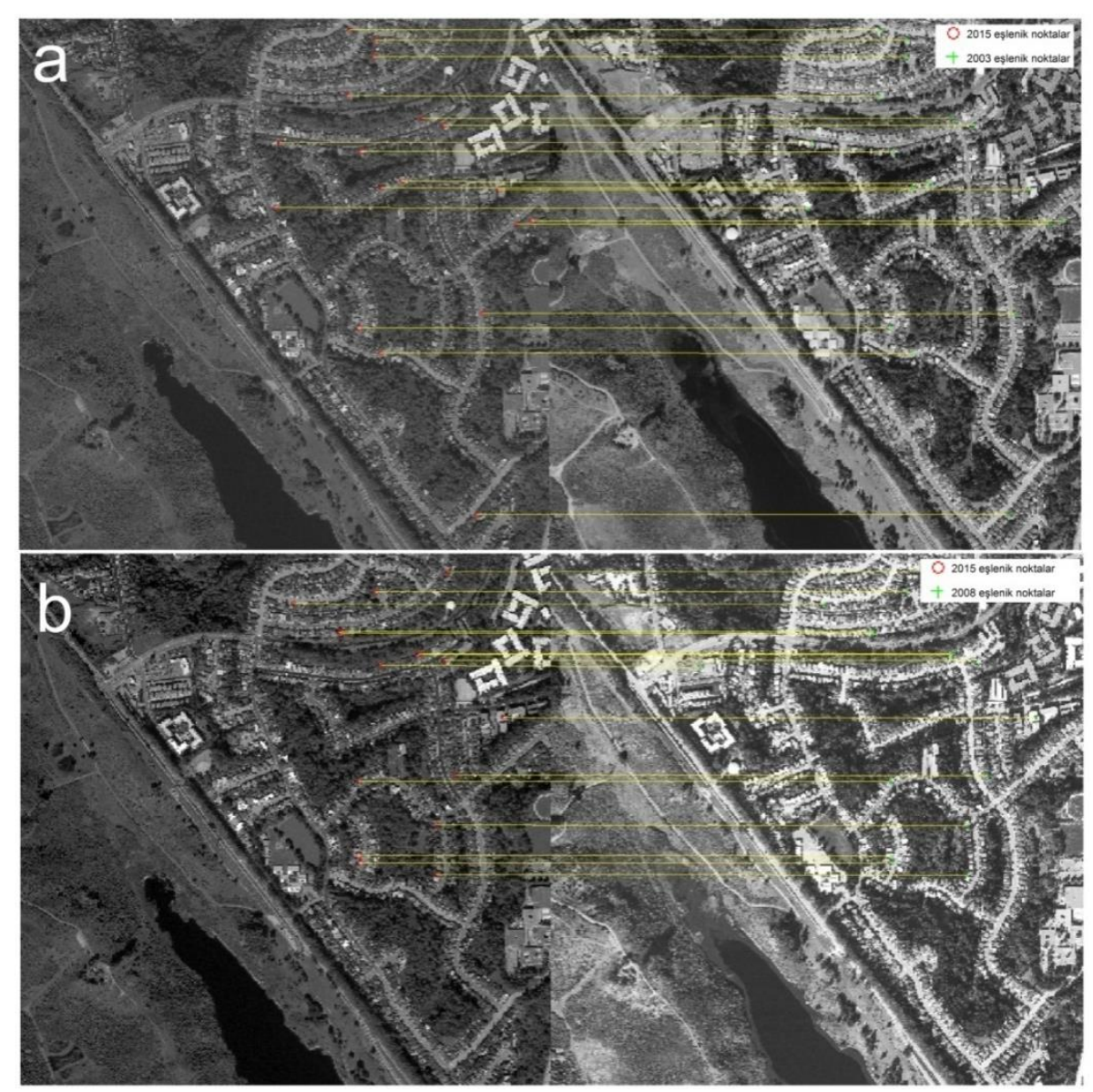

Şekil 4. (a) 2003 - 2015 (b) 2008 - 2015 tarihli hava görüntüleri üzerinde güçlü eşlenik noktalar

\section{Sonuçlar ve Öneriler}

Çalışmada önerilen yaklaşım kullanılarak yapılan otomatik görüntü çakıştırma işlemleri sonrasında her görüntü için $\mathrm{KOH}$ değerleri hesaplanmış ve dönüşüm sonrası elde edilen konumsal doğruluk düzeyleri ortaya koyulmuştur (Tablo 1).

Tablo 1'de ilgili görüntüler üzerinde tespit edilmiş olan her bir eşlenik nokta çifti için dönüşüm sonrası hesaplanan koordinat bileşenleri ile referans değerler arasındaki karesel farklar $\left(\Delta \mathrm{x}^{2}\right.$, $\left.\Delta y^{2}\right)$ gözlemlenebilmektedir. Söz konusu değerler incelendiğinde; 2003 görüntüsü için maksimum karesel farklar toplamının $0.69 \mathrm{~m}, 2008$ görüntüsü için ise $0.68 \mathrm{~m}$ düzeylerinde olduğu tespit edilmiştir. $\mathrm{Bu}$ aşamada eşitlik (5) yardımıyla; 2003 görüntüsü için $\pm 0.61 \mathrm{~m}, 2008$ görüntüsü için ise $\pm 0.53 \mathrm{~m} \mathrm{KOH}$ değerleri hesaplanmıştır. Söz konusu konumsal doğruluk düzeylerinin birçok uygulama için yeterli düzeyde olduğu anlaşılmaktadır. Çakıştırma aşaması sonrasında jeo-referanslı olarak kaydedilen sonuç görüntüleri Şekil $5 \mathrm{a}$ ve b de görülebilmektedir.

$$
K O H= \pm \sqrt{\frac{1}{n} \sum_{i=1}^{n}\left(x_{i}-x_{i}^{\prime \prime}\right)^{2}+\left(y_{i}-y_{i}^{\prime \prime}\right)^{2}}
$$

Eşitlikte; $n$ her bir görüntü üzerindeki toplam nokta sayısın1, $\left(x_{i}, y_{i}\right)$ referans görüntü UTM koordinat sisteminde her $i$ noktası için koordinat bileşenlerini, $\left(x_{i}{ }^{\prime \prime}, y_{i}{ }^{\prime \prime}\right)$ dönüşüm sonrası her $i$ noktası için hesaplanan koordinat bileşenlerini ifade etmektedir. 
Tablo 1. Projektif dönüşüm sonrası her bir nokta için hatalar

\begin{tabular}{|c|c|c|c|c|}
\hline Görüntü & Nokta No & $\Delta \mathrm{x}^{2}(\mathrm{~m})$ & $\Delta y^{2}(m)$ & $\sum(\mathrm{m})$ \\
\hline \multirow{14}{*}{2003} & 1 & 0.325 & 0.176 & 0.501 \\
\hline & 2 & 0.425 & 0.039 & 0.464 \\
\hline & 3 & 0.086 & 0.001 & 0.087 \\
\hline & 4 & 0.442 & 0.034 & 0.476 \\
\hline & 5 & 0.244 & 0.008 & 0.252 \\
\hline & 6 & 0.566 & 0.000 & 0.567 \\
\hline & 7 & 0.460 & 0.031 & 0.491 \\
\hline & 8 & 0.301 & 0.099 & 0.400 \\
\hline & 9 & 0.094 & 0.000 & 0.094 \\
\hline & 10 & 0.000 & 0.372 & 0.372 \\
\hline & 11 & 0.222 & 0.139 & 0.360 \\
\hline & 12 & 0.217 & 0.033 & 0.250 \\
\hline & 13 & 0.069 & 0.095 & 0.163 \\
\hline & 14 & 0.645 & 0.046 & 0.691 \\
\hline \multirow{11}{*}{2008} & 1 & 0.142 & 0.026 & 0.169 \\
\hline & 2 & 0.067 & 0.006 & 0.073 \\
\hline & 3 & 0.087 & 0.028 & 0.115 \\
\hline & 4 & 0.036 & 0.088 & 0.124 \\
\hline & 5 & 1.054 & 0.037 & 1.090 \\
\hline & 6 & 0.155 & 0.042 & 0.197 \\
\hline & 7 & 0.654 & 0.022 & 0.676 \\
\hline & 8 & 0.410 & 0.035 & 0.445 \\
\hline & 9 & 0.037 & 0.014 & 0.051 \\
\hline & 10 & 0.036 & 0.002 & 0.038 \\
\hline & 11 & 0.063 & 0.007 & 0.070 \\
\hline
\end{tabular}

$\mathrm{Bu}$ çalışmada değişik sensörlerle tarafından farklı zamanlarda kaydedilmiş çok-bantlı uzaktan algılanmış görüntülerin otomatik çakıştırılmasına yönelik özellik tabanlı bir yaklaşım geliştirilmiştir. Önerilen yaklaşım sayesinde alım noktası konumlarının farklılığı, dönüklük, ölçek gibi geometrik parametrelerden bağımsız olarak özellik çıkarma eşleştirme ve çakıştırma işlemleri yüksek doğrulukla gerçekleştirilebilmiştir. Bununla birlikte uzaktan algılanmış görüntü verilerinde çoğu zaman aynı detayların sahip olabildiği radyometrik, spektral farlilıklar ve gürültü gibi etmenler otomatik çakıştırma performansını olumsuz yönde etkileyebilmektedir. $\mathrm{Bu}$ durum bir yandan SURF algoritması ile tespit edilen ilgi noktası sayısını azaltabilmekte bir yandan da her iki görüntü çifti üzerinde uygun konumsal dağılımlı arzulanan sayıda güçlü eșlenik nokta tespitini güçleştirmektedir. Önerilen yaklaşımda görüntü iyileştirme aşamasında uygulanan ana bileşenler dönüşümü sayesinde görüntülerin spektral ve radyometrik karakteristiğinden kaynaklı bu tür olumsuzluklar çok-bantlı verideki değerli bilgiden faydalanılarak minimum düzeye indirgenmiştir. $\mathrm{Bu}$ sayede hem SURF özellik çıkarma performans1 hem de otomatik çakıştırma işleminin konumsal doğruluğu artmıştır.

Gelecek çalışmalarda önerilen yaklaşım üzerinde, tespit edilen eşlenik noktaların konumsal dağılımını dikkate alabilecek ve elde edilen güçlü eşlenik nokta sayısının arttırabilecek şekilde çeşitli iyileştirmeler yapılması amaçlanmaktadır. Ayrıca yaklaşımın spektral bant sayısı daha fazla yüksek konumsal çözünürlüklü farklı veri setleri üzerinde performansının irdelenmesi amaçlanmaktadır.
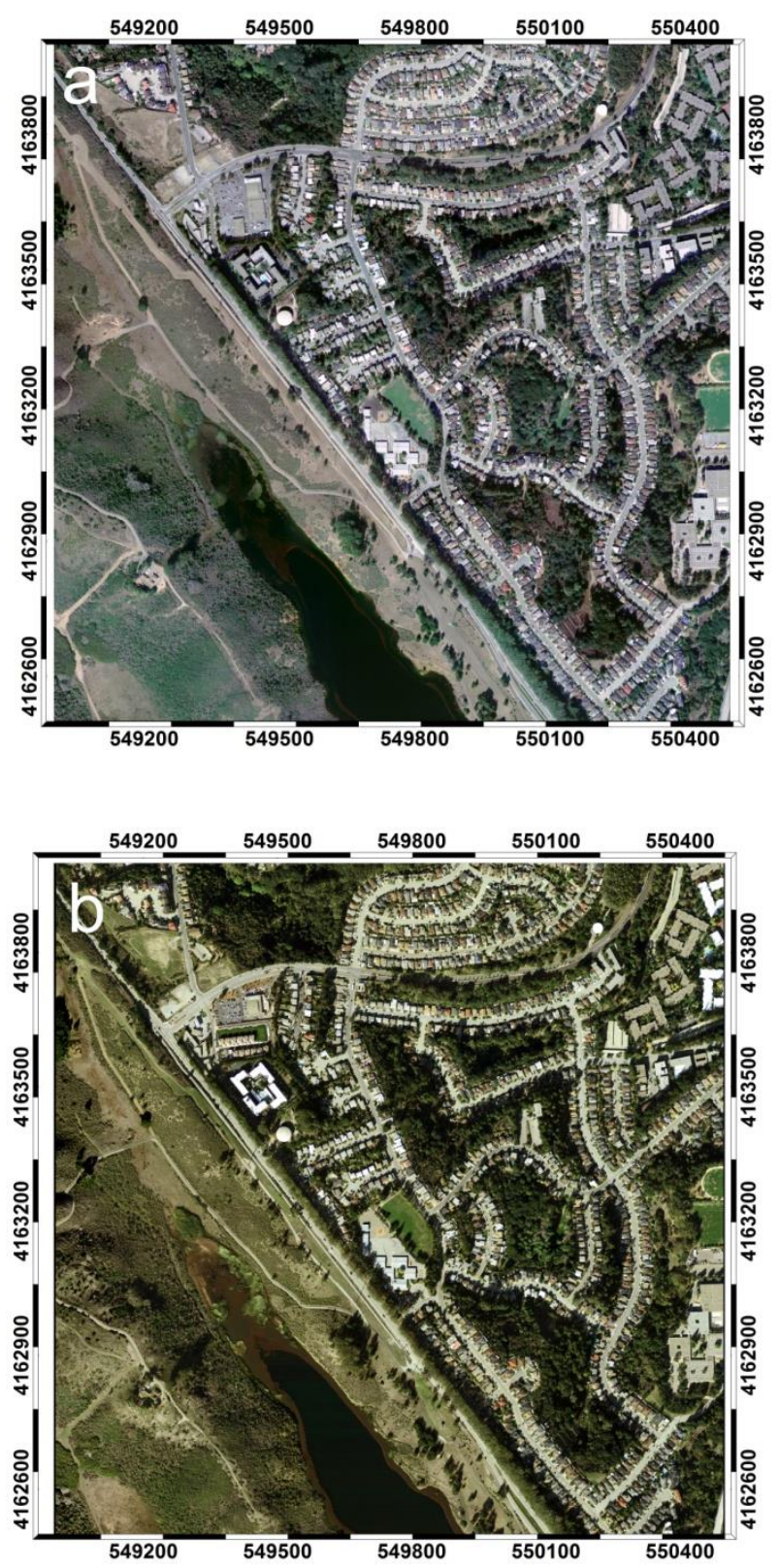

Şekil 5. Otomatik çakıștırılması yapılmış (a) 2003 ve (b) 2008 tarihli hava görüntüleri

\section{Teşekkür}

Yazar çok bantlı hava görüntülerini sağladıkları için GLCF (Global Land Cover Facility) organizasyonuna teşekkür eder. 


\section{Kaynakça}

Acar, H., Karsli, F., Dihkan, M. (2017). Automatic 3D Coordinate Extraction from High Resolution Digital Aerial Images. Journal of the Indian Society of Remote Sensing, 45(2), 209-216.

Bay, H., Ess, A., Tuytelaars, T., Van Gool, L. (2008). Speeded-up robust features (SURF). Computer vision and image understanding, 110(3), 346359.

Brown, L. G. (1992). A survey of image registration techniques. ACM computing surveys (CSUR), 24(4), 325-376.

Brown, M., Lowe, D. G. (2002). Invariant features from interest point groups. In: $B M V C, 4$.

Fischler, M. A., Bolles, R. C. (1981). Random sample consensus: a paradigm for model fitting with applications to image analysis and automated cartography. Communications of the ACM, 24(6), 381-395.

Fonseca, L. M., \& Manjunath, B. S. (1996). Registration techniques for multisensor remotely sensed imagery. $P E \& R S$ Photogrammetric Engineering \& Remote Sensing, 62(9), 1049-1056.

Gonçalves, H., Corte-Real, L., Gonçalves, J. A. (2011b). Automatic image registration through image segmentation and SIFT. IEEE Transactions on Geoscience and Remote Sensing, 49(7), 2589-2600.

Gonçalves, H., Gonçalves, J. A., Corte-Real, L. (2011a). HAIRIS: A method for automatic image registration through histogram-based image segmentation. IEEE transactions on image processing, 20(3), 776-789.
Harris, C., Stephens, M. (1988). A combined corner and edge detector. In: Alvey vision conference, 15(50), 10-5244.

Hartley, R., Zisserman, A. (2003). Multiple view geometry in computer vision. Cambridge university press.

Li, Q., Wang, G., Liu, J., Chen, S. (2009). Robust scale-invariant feature matching for remote sensing image registration. IEEE Geoscience and Remote Sensing Letters, 6(2), 287-291.

Lowe, D. G. (2004). Distinctive image features from scale-invariant keypoints. International journal of computer vision, 60(2), 91-110.

Ma, W., Wen, Z., Wu, Y., Jiao, L., Gong, M., Zheng, Y., Liu, L. (2017). Remote sensing image registration with modified SIFT and enhanced feature matching. IEEE Geoscience and Remote Sensing Letters, 14(1), 3-7.

Rosten, E., Drummond, T. (2006). Machine learning for high-speed corner detection. In: European conference on computer vision, 430-443, Springer, Berlin, Heidelberg.

Smith, S. M., Brady, J. M. (1997). SUSAN - a new approach to low level image processing. International journal of computer vision, 23(1), 45-78.

Yang, K., Pan, A., Yang, Y., Zhang, S., Ong, S. H., Tang, H. (2017). Remote sensing image registration using multiple image features. Remote Sensing, 9(6), 581.

Zitova, B., Flusser, J. (2003). Image registration methods: a survey. Image and vision computing, 21(11), 977-1000. 